\title{
Reasons for the Coexistence of Different Distribution Channels: An Empirical Test for the German Insurance Market
}

\section{Lucinda Trigo-Gamarra}

Department of Economics - Chair of Money and Credit, University of Rostock, Ulmenstrasse 69, Rostock 18057, Germany.

E-mail: lucinda.trigo-gamarra@uni-rostock.de

Private insurance markets in Germany are characterized by the coexistence of different distribution systems. Insurance products are mainly distributed both by independent and dependent agents. Economic theory provides different explanations for the coexistence of distribution channels: the product quality hypothesis states that independent agents provide both insurers and customers with higher service intensity and product quality and, therefore, remain on the market. We sent a written questionnaire to German insurance intermediaries designed to measure service quality. Our analysis shows that a higher level of service quality among independent agents supports the product quality hypothesis.

The Geneva Papers (2008) 33, 389-407. doi:10.1057/gpp.2008.16

Keywords: insurance intermediation; service quality; distribution systems

\section{Introduction}

The liberalization of the European insurance sector in 1994 has led to major changes in the highly regulated German insurance market. Now, consumers face more insurance products and providers, and private old-age and health provision is gaining importance because of the decline in public provision in these sectors. Both factors have led to private customers' increasing need for advice. This need is attributed to the characteristics of insurance products, often characterized as credence or trust goods, which present high information asymmetries.

Generally, insurance intermediaries act as experts and help to inform customers, so the insurance sector is characterized by different types of insurance intermediaries: exclusive (dependent) agents act on behalf of one or more selected insurance companies and are allowed to sell only the corresponding products, while independent insurance agents (insurance brokers) act primarily on behalf of the insurance customer and are free to choose the insurance products they sell and the companies with which they work. However, both exclusive and independent agents are paid for their services on a commission basis by the insurers. In many cases, insurance companies distribute their products via both independent and exclusive intermediaries but, in the German market, exclusive agents had been the dominant distribution channel until the liberalization of the industry. Since then, independent agents have gained importance. Thus, an explanation for the growing importance of the independent insurance agency system is needed. 
The existing literature provides two main explanations for the coexistence of different distribution channels: the product quality hypothesis and the market imperfections hypothesis. The product quality hypothesis states that the two systems coexist because they differ in the services they offer and the clientele they attract, and the higher costs of the independent agency system are compensated for by a higher level of service intensity and product quality compared to that provided by exclusive agents. ${ }^{1}$ The market imperfections hypothesis, on the other hand, states that exclusive agents and independent agents do not differ in the level of service intensity and product quality they offer to the customer but that the two systems coexist because of prevailing information asymmetries, a lack of market transparency and other differences between the two distribution channels. The more cost-intensive independent agent-based distribution channel might exist because of the information asymmetries. ${ }^{2}$

To analyze the coexistence of different channels of distribution in German insurance markets, this paper empirically tests the product quality hypothesis by analyzing differences in service intensity and output performance of independent and exclusive agents. A direct test of the market imperfections hypothesis would require testing for differences in the cost levels of different intermediary types by comparing costs incurred by exclusive and independent agents or agencies, but data for this are highly limited. In the German insurance market, most insurers work with both independent and exclusive insurance agents, so our hypotheses are tested directly by using indicators that measure the service intensity and selected performance indicators provided by exclusive and independent insurance agents. These service quality differences may then help to explain why independent intermediaries have gained importance in the market since liberalization in 1994. To evaluate the hypotheses, an online survey among approximately 3,500 exclusive and independent German insurance agencies was carried out in the spring of 2005.

This study offers an answer to the questions of how different insurance distribution channels can coexist and how the liberalization of the market has affected their relative importance. Thus, it adds new findings to the existing research on the coexistence of distribution channels in insurance markets and is the first study to analyze the question for the German market.

This paper is organized as follows: the following section contains the theoretical background on the coexistence of dependent and independent insurance agents and reviews previous research. The next section illustrates the empirical design of this study, overviews the applied variables and presents the estimation approach. The subsequent section presents the main descriptive results and the results of the multivariate estimations. Conclusions are drawn in the last section.

\section{Theoretical background and previous research}

There is already an important strand of literature that deals with insurance intermediaries by mainly focusing on the coexistence of independent insurance

\footnotetext{
${ }^{1}$ See, for example, Barrese and Nelson (1992).

2 Joskow (1973); Cummins and VanDerhei (1979); Weiss (1990).
} 
brokers and exclusive agents. Two main hypotheses for the coexistence have been derived primarily based on evidence for the U.S. insurance market.

The market imperfections hypothesis states that two distribution systems, via exclusive agents and via independent agencies, do not differ in the quality they offer to the customer. The explanation for the coexistence of both systems lies instead in prevailing information asymmetries, a lack of market transparency and the incomparability of the two distribution channels. Thus, the more cost-intensive independent agent-based distribution channel might continue to exist because of the information asymmetries in the market. ${ }^{3,4}$ Those asymmetries may be attributed to a slow diffusion of information on insurance markets or to high search costs which prevent inefficient firms from being identified. ${ }^{5}$ The result is that both intermediary types coexist on the market in a pooling equilibrium, even though the higher costs of the independent agency system are not reflected by a higher level of service quality. In the long run, however, the information asymmetries might decrease, leading to a declining market share for independent intermediaries.

According to the product quality hypothesis, the choice of the independent agency system by insurance companies is justified by the higher level of service quality delivered by independent agents. This can be analyzed from a supply-side angle, where it is the insurance company which receives a higher level of quality of the service from independent agents, ${ }^{6}$ or from a demand-side angle, where insurance brokers provide superior services to the customers (e.g., better information, superior counseling quality), which leads to increased demand from customers for these services. As this study focuses primarily on the consequences of the liberalization of the insurance market on the need for customer counseling, the service quality is tested from the demand-oriented angle. ${ }^{7}$

Previous literature provides several demand-side explanations for the higher service intensity and product quality of independent agents, but the central reasoning is found in the seminal paper by Grossman and Hart. ${ }^{8}$ The authors stated that, in the U.S., the difference in ownership of the central asset, the client list, leads to higher investments in the client list by independent agents compared to exclusive agents. These higher investments are reflected in the effort with which the insurance policy is chosen and designed, and in the level of efficiency when dealing with claims settlement. The higher effort results in a higher level of service quality. Although, in the German market, it is the insurance firm which owns the client list, insurance brokers may still have incentives to provide higher service quality, as they are subject to stricter liability

\footnotetext{
${ }^{3}$ Ibid.

${ }^{4}$ The main reason for the higher cost of the independent agency system in the U.S. market is given by the ownership of the client list by the independent agent. In the German insurance market, the independent agent does not own his or her client list, and it is the insurance firm which decides on the renewal of the contract (e.g. Grieß and Zinnert (1997)). Even so, independent agents usually receive high commission levels from the insurance firms to ensure that the independent agent places the most profitable business with them (e.g., Scheiper (1996)).

${ }^{5}$ Berger et al. (1989); Dahlby and West (1986).

${ }^{6}$ For example, Regan (1997); Regan and Tennyson (1996); Anderson et al. (1998).

${ }^{7}$ Finsinger and Schmid (1994).

${ }^{8}$ Grossman and Hart (1986).
} 
rules. ${ }^{9}$ For example, according to German law, independent insurance brokers are liable for losses from poor counseling, whereas insurance firms, not their agents, are liable for the actions of their exclusive agents. Thus, insurance brokers may face higher incentives to pursue a more detailed risk analysis and careful design of the chosen policy.

Other explanations for a higher service intensity provided by independent agents contend that, in contrast to exclusive agents who work only for a single or a few insurance firms, insurance brokers compare products of many different providers and attain more information, so they are able to give better-informed advice to the customer and to reduce the customer's search costs. ${ }^{10}$ Higher service quality could also consist of better ongoing monitoring of the insurer by brokers for the purposes of renewal, including screening different insurers for appropriate coverages, low prices and financial stability. ${ }^{11}$ Mayers and Smith, and Barrese and Nelson also stated that independent agents are more capable of dealing with conflicts between insurers and policy holders, as they can threaten to move the customer to another insurer if the insurance company acts unreasonably. ${ }^{12}$

To summarize, several theoretical arguments provided by previous literature support the product quality hypothesis. Following these arguments, the result would be a separating equilibrium in the market for insurance intermediation where independent agents engage in more complex insurance lines, where the customer's need for information is comparatively high, and a high level of service quality is of great importance. In contrast, exclusive agents have a comparative advantage in the distribution of standardized insurance products because information and counseling of the customer are of lower importance in these cases and customers may prefer lower cost to more counseling.

A number of studies have addressed differences in performance and service quality of different insurance distribution channels. However, the majority of previous studies dealing with this issue have not measured provided services of insurance agents directly; instead, cost and revenue or profit functions of insurers working exclusively with exclusive agents and exclusively with independent agents have been estimated to compare the cost and revenue levels of the two distribution systems. The results have been mixed: while in most cases, independent agents were found to deliver higher service quality, ${ }^{13}$ some studies did not find any significant differences in service quality or even evidence for better performance of exclusive agents. ${ }^{14}$ Only two studies have compared exclusive and independent agents on the German market: Eckardt employed mean differences parametric tests to identify differences in quantitative and qualitative variables describing the information and counseling behavior of agents and to show that

\footnotetext{
${ }^{9}$ See, for example, Nell and Traub (1994).

${ }^{10}$ Posey and Tennyson (1998).

11 Regan (1997).

12 Mayers and Smith (1981); Barrese and Nelson (1992).

${ }^{13}$ For example, Cummins and Weisbart (1977); Barrese and Nelson (1992); Barrese et al. (1995); Berger et al. (1997).

${ }^{14}$ For example, Joskow (1973); Etgar (1976); Klumpes (2004).
} 
independent agents provide higher information quality. ${ }^{15}$ In a second study using the same data, Eckardt used multivariate estimations to show that the information quality provided by insurance intermediaries increases with their independence from insurance companies. ${ }^{16}$ However, Eckardt did not center on the explanation for the coexistence of both distribution channels, but on the working of signaling instruments in the market for insurance intermediation, among them the intermediary type.

\section{Empirical design and estimation approach}

To directly measure service intensity and performance by insurance intermediaries in the German market, we generated a data set from an online survey sent to 3,500 German exclusive and independent insurance intermediaries in the spring of 2005. The generation of this primary data set was necessary, as data about the information and counseling activities of intermediaries, as well as about the outcomes of their counseling, were not available before. The e-mail addresses were randomly chosen from sources like online directories, registers of members of professional organizations, and registers of members of chambers of commerce and industry. ${ }^{17}$ The final data set consists of 608 answered questionnaires, with 58.4 percent $(N=355)$ from exclusive and 41.6 percent $(N=253)$ from independent agents. Tied or exclusive agents belonging to a single or several insurance companies or an insurance group have been classified as exclusive agents. Insurance brokers and financial consultants have been classified as independent agents. ${ }^{18}$ Detailed information on the exact number of insurance intermediaries in the single group is not available in the German market, only rough estimates are published by the German Insurance Association (GDV). ${ }^{19}$ We did not include part-time intermediaries into our analysis, as this group only accounts for a very small amount of the premium income of the industry. According to the GDV, the main part of the premium income is generated by exclusive agents, independent agents, and insurance brokers. ${ }^{20}$ Thus, our sample covers the main distribution channels. ${ }^{21}$

${ }^{15}$ Eckardt (2002).

${ }^{16}$ Eckardt (2007).

${ }^{17}$ There was no legal duty to register as an insurance intermediary in the German market until 2007. Thus, no central register was available from which to obtain addresses of insurance intermediaries and it was not possible to rule out that an agency received more than one survey. To ensure that only one member of an insurance agency answered the questionnaire, if it happened that more than one member of an agency received an e-mail, we included in the cover letter to the survey a remark to the effect that only one member of each agency respond to the survey. Further, it was not possible to determine the exact number of independent and exclusive agents in the initial sample, as the sources used for obtaining the email addresses did not always reveal the status of the intermediary.

${ }^{18}$ Financial consultants are usually not tied to one or several companies, so they have been classified as independent agents, although the title is not linked to any requirements. Their share in the group of independent agents is very small, representing only 21 of 253 cases.

19 GDV (2004).

${ }^{20}$ GDV (2002).

${ }^{21}$ However, due to missing information about the total population, the possibility of a selection bias cannot be excluded. See also the last section for a remark on this problem and a task for future research. 
To identify the possible influence of differences in qualifications on the service quality, we asked for attributes of the interviewee, including age, professional experience (in years), professional qualification level (educational level and additional skills), and membership in a professional organization. For the educational level, the different training levels available in the German insurance market were classified from 1 to 6, with level 1 the lowest (corresponding to the qualification level of Servicefachmann/frau Versicherungen, which is equivalent to $240 \mathrm{~h}$ of practical and service-oriented training) and level 6 the highest (university degree in economics with a specialization in insurance).

Structural variables surveyed contain information about firm size (measured by the number of employees), product range (number of services provided besides the mediation of insurance products), and share of complex insurance products sold (oldage provisions, commercial insurance, industrial insurance, and private health insurance products were classified as complex insurance products). Compared to more standardized insurance lines, the conditions of insurance for more complex lines usually are formulated individually by the intermediary, according to the customer's needs and preferences.

To test the product quality hypothesis, it is necessary to define and measure service quality. According to Cummins and Doherty, and Eckardt, intermediaries provide information and advisory, bargaining, and administrative services. ${ }^{22}$ Based on the different service components, we selected several indicators for the input quality of the intermediary's services belonging to the categories of acquisition and transfer of information, as well as documentation activities. They are thought to measure the service intensity of the intermediary's services. By taking into account these activities that are carried out during the counseling process, we are able to analyze if independent agents show a higher level of service intensity, as predicted by theory. The second group of quality indicators contains indicators for the output quality. The lapse rate and the share of new customers in the intermediary's portfolio are considered, in addition to the contract conclusion rate. We focus on services the agents provide to their clients, as well as on output indicators which are primarily in the interest of the client, as this study provides a demand side-oriented view of service quality. To summarize, this approach allows us to analyze in a first step if independent intermediaries show a higher level of service intensity measured by the input indicators, and in a second step if this higher level of input activities translates into better performance by independent agents. Thus, by this two-step approach, we are able to test the product quality hypothesis.

We start with a discussion of the input quality indicators which represent the dependent variables in models $1-4$ :

- Model 1: Working time information acquisition: The variable is considered to measure whether there is a difference between the two agency types in time spent on information acquisition. The more time spent on information acquisition, the better advice the intermediary should be able to give. Independent agents are expected to

\footnotetext{
${ }^{22}$ Cummins and Doherty (2006); Eckardt (2007).
} 
spend a higher share of working time on information acquisition, as they have to collect and analyze information on a larger number of suppliers and products. The variable is measured as the ratio of working time spent on information acquisition to total working time.

- Model 2: Importance of rating agencies: This variable measures whether the two intermediary types differ in the importance and valuation they attach to information provided by rating agencies. Rating agencies help to overcome information asymmetries in insurance markets by analyzing and comparing the performance of different insurance firms and products. As these rating agencies do not act on behalf of insurance firms or customer associations and they specialize in insurance topics, their information tends to be objective and of high quality. Independent agents are expected to attach a higher value to the information by rating agencies, as they have to compare a higher number of products and providers to find the best suitable product for the customer. To measure the importance of information by rating agencies, we use a five-point rating scale ranging from $1=$ very important to $5=$ completely unimportant.

- Model 3: Risk analysis: The variable measures whether the two intermediary types vary in the complexity with which they perform risk analysis. To determine the insurance needs of a customer, the intermediary must first analyze the customer's risk profile, including personal characteristics, risk preferences, the customer's financial and professional situation, and the customer's existing insurance coverage. Because of the high volume and complexity of the information, service quality is expected to increase as the level of complexity with which the risk analysis is carried out increases; independent agents are expected to use more complex instruments to carry out the risk analysis. The respondents were asked to classify their risk analysis process according to three categories: 1) subjective classification of the client's risk profile, 2) grading of the client's risk profile in given risk categories, 3) computerassisted determination of the customer's risk profile. ${ }^{23}$ Thus, the risk analysis process is measured on a three-point scale, with the degree of complexity ranging from 1 to 3.

- Model 4: Documentation counseling interview: This variable measures whether the two intermediary types vary with regard to the documentation of counseling interviews. Possible poor counseling by the intermediary can be detected only if a record of the counseling interview exists; this record could prove that the intermediary failed to inform the customer about relevant characteristics of the insurance product. Until the summer of 2007, there was no legal duty in Germany for an insurance intermediary to deliver a record of the counseling interview. Thus, the voluntary delivery of a record can be seen as a signal of higher service quality. We expect independent intermediaries to record their counseling interviews more frequently, as independent brokers are subject to stricter liability rules. The variable is measured with a binary variable $(0 / 1)$ and takes the value of 1 if the counseling

\footnotetext{
${ }^{23}$ The categories were determined according to information obtained from personal interviews with industry experts before conducting the survey. A copy of the survey is available from the author on request.
} 
interview is documented and a copy of the record is both stored and given out to the customer.

We now turn to those indicators that are output-oriented, that is, which measure the output performance of the intermediary.

- Model 5: Contract conclusion rate: The variable is surveyed to determine if different intermediary types vary with regard to rate of counseling interviews which lead to the conclusion of an insurance contract. The higher the percentage of counseling interviews that lead to the signing of an insurance contract, the more satisfied the customers are with the counseling process. Thus, it can be expected that the more successful an intermediary is likely to be in analyzing the relevant information and choosing suitable contracts for the customers, the higher the contract conclusion rate is going to be. The variable is measured as the percentage of counseling interviews which result in customers actually signing an insurance contract.

- Model 6: Lapse rate automobile insurance: This variable measures whether the two intermediary types vary with regard to the rate of insurance contracts which are cancelled within the first year of signing the contract. A cancellation of an insurance contract during the first year demonstrates probable customer dissatisfaction and is an indicator of a lower level of advisory quality by the intermediary. Thus, if the product quality hypothesis holds true, independent agents should show lower lapse rates. The variable is measured as the ratio of automobile insurance contracts cancelled within the first year to the total number of automobile insurance contracts.

- Model 7: Share of turnover of new customers: This variable measures whether the two intermediary types vary with regard to the share of financial turnover by new customers. A higher share of turnover generated by new customers indicates faster growth of the agency, which can be explained by a higher perceived level of quality leading to higher demand by new customers. The variable is measured by the share of turnover which is gained by the conclusion of contracts with new customers.

These seven indicators are the dependent variables in the multivariate models. The following variables are taken into account as explanatory variables in all seven models:

- Intermediary type: A dummy variable differentiates between exclusive (0) and independent insurance agents (1). Following the product quality hypothesis, we expect that independent agents supply better service quality, and that the variable will show a positive sign.

- Firm size: This variable is measured on the basis of the number of employees, as financial data are not available. The expected influence on service quality is positive, as we assume increasing economies of scale to be realized during the acquisition and procession of information. This would make it possible to provide a given level of information at lower costs.

- Product range describes the number of additional services the intermediary offers besides the mediation of insurance products. Services like investment counseling, financial advice, investment fund management, asset management, and real estate 
agency are considered. The expected influence on service quality is positive, as economies of scope are expected to exist for the supply of different services. For example, information gained about the risk profile of a customer can be used to supply the customer with other products. The costs for obtaining the information can then be distributed among different services.

- Share of complex insurance products specifies the ratio of complex insurance policies (policies belonging to the insurance lines of old-age provision, private health insurance, commercial insurance, and industrial insurance) to the total number of policies. The variable ranges between 0 and 1 , and the expected influence on advisory service quality is positive since intermediaries with a higher share of complex insurance products in their portfolios have to meet higher requirements in the acquisition and transfer of information, which should lead to higher service quality.

- Membership in a professional organization: This dummy variable takes the value of 1 if the intermediary is member in a professional organization and 0 otherwise. Membership in a professional organization is often linked to the fulfillment of certain quality standards (e.g., minimum qualification level, rules of conduct, professional indemnity insurance), so it can signal a higher level of quality. Thus, a positive influence on the indicators is expected.

To summarize, we formulate the following hypotheses:

H1: Independent agents show higher levels of service quality compared to exclusive agents, as measured by the analyzed service quality indicators.

$\mathrm{H} 2$ : The service quality provided is positively influenced by firm size, product range, share of complex insurance products in the portfolio, and membership in a professional organization.

A separating equilibrium may result in the market if the product quality hypothesis holds true: Independent agents may focus on more complex insurance products, while exclusive agents sell more standardized insurance products. To test the existence of such a separating equilibrium, we formulate hypothesis 3 :

H3: Independent agents are engaged in more complex insurance lines than are exclusive agents.

\section{Results}

Table 1 summarizes the main descriptive statistics that compare the mean and median values of the structural and exogenous, as well as the dependent variables for the groups of independent and exclusive agents, and the total sample.

The results for the structural variables show that exclusive agents have, on average, a larger client base: tied agents act as agents for an average of 1,565 customers, whereas independent brokers act on behalf of an average of only 1,106 clients. The reason for this difference could lie in the lower commission levels and less timeintensive services by exclusive agents, which allow the agent to handle more clients. As to the qualification level and professional experience, the groups do not appear to differ: both exclusive and independent agents show the same median qualification level 
Table 1 Descriptive results

\begin{tabular}{|c|c|c|c|c|c|c|}
\hline & \multicolumn{2}{|c|}{ Exclusive agents } & \multicolumn{2}{|c|}{ Independent agents } & \multicolumn{2}{|c|}{ Total } \\
\hline & Mean & Median & Mean & Median & Mean & Median \\
\hline \multicolumn{7}{|l|}{ Structural variables } \\
\hline Number of customers & 1565 & 1200 & 1106 & 575 & 1352 & 970 \\
\hline Qualification level & 2.75 & 2.00 & 2.75 & 2.00 & 2.75 & 2.00 \\
\hline Professional experience & 16.93 & 15.00 & 16.59 & 16.00 & 16.79 & 15.00 \\
\hline Firm size & 2.94 & 1.5 & 5.08 & 2.00 & 3.83 & 1.5 \\
\hline Product range & 3.80 & 4.00 & 3.37 & 4.00 & 3.62 & 4.00 \\
\hline Share of complex insurance products & 0.39 & 0.36 & 0.44 & 0.40 & 0.42 & 0.37 \\
\hline Member in a professional organization & 0.29 & 0.00 & 0.35 & 0.00 & 0.32 & 0.00 \\
\hline \multicolumn{7}{|l|}{ Input and output quality indicators } \\
\hline Working time information acquisition & 0.21 & 0.20 & 0.35 & 0.30 & 0.27 & 0.25 \\
\hline Importance of rating agencies & 2.32 & 2.00 & 1.88 & 2.00 & 2.11 & 2.00 \\
\hline Risk analysis & 1.92 & 2.00 & 1.96 & 2.00 & 1.94 & 2.00 \\
\hline Documentation of counseling interview & 0.28 & 0.00 & 0.57 & 1.00 & 0.40 & 0.00 \\
\hline Contract conclusion rate & 0.48 & 0.50 & 0.68 & 0.75 & 0.56 & 0.50 \\
\hline Lapse rate automobile insurance & 0.04 & 0.00 & 0.02 & 0.00 & 0.03 & 0.00 \\
\hline Share of turnover by new customers & 0.24 & 0.20 & 0.31 & 0.20 & 0.27 & 0.20 \\
\hline
\end{tabular}

of 2 (corresponding to the qualification level of Versicherungsfachmann-/frau, which is equivalent to a 230-h theoretical and practical training course) for both groups. Further, both groups show a mean experience level of nearly 17 years.

Firm size clearly differs between the two types of agents: Exclusive agencies have 2.94 employees on average, while independent agencies are larger, with 5.08 employees at the mean. Both groups offer their customers a comparable range of products in addition to insurance products, but independent agents have a larger share of complex insurance products in their portfolios. Independent intermediaries are also more often members in professional organizations. Concerning the quality indicators which serve as dependent variables in the estimations, independent agents show higher levels for all indicators with two exceptions: according to the median values, both intermediary types do not vary regarding the importance they attach to information by rating agencies and the level of complexity with which the risk analysis is carried out (Table 2).

In a next step, our multivariate estimations show that the differences between the two groups continue to exist in most cases when considering the chosen additional exogenous variables. Table 2 shows the results of models $1-4$, which analyze the impact of the exogenous variables on the four selected input quality indicators. Table 3 presents the results of models 5-7, which analyze the three output quality indicators. Multicollinearity between the independent variables was tested before conducting the multivariate estimations, but no indication could be found. ${ }^{24}$ ${ }^{24}$ The use of self-reporting variables, as considered in this study, raises the problem of a possible response
bias. Interviewees asked about their performance tend to exaggerate. However, it can be assumed that 
Table 2 Estimation results - input quality indicators

\begin{tabular}{|c|c|c|c|c|}
\hline & $\begin{array}{l}\text { Model 1: Share } \\
\text { of working time } \\
\text { spent on } \\
\text { information- } \\
\text { gathering }\end{array}$ & $\begin{array}{c}\text { Model 2: } \\
\text { Importance of } \\
\text { rating agencies }\end{array}$ & $\begin{array}{l}\text { Model 3: } \\
\text { Design of } \\
\text { risk analysis }\end{array}$ & $\begin{array}{c}\text { Model 4: Record } \\
\text { of counselling } \\
\text { interview } \\
(\text { Yes } / \text { No })\end{array}$ \\
\hline Intermediary type (independent $=1$ ) & $\begin{array}{l}0.769^{* * *} \\
(7.628)\end{array}$ & $\begin{array}{l}-0.428 * * * \\
(-3.706)\end{array}$ & $\begin{array}{c}0.043 \\
(0.381)\end{array}$ & $\begin{array}{l}1.155^{* * * *} \\
(5.414)\end{array}$ \\
\hline Firm size & $\begin{array}{c}0.002 \\
(0.300)\end{array}$ & $\begin{array}{c}0.001 \\
(0.103)\end{array}$ & $\begin{array}{l}-0.044 * * \\
(-2.409)\end{array}$ & $\begin{array}{c}-0.005 \\
(-0.384)\end{array}$ \\
\hline Product range & $\begin{array}{c}-0.041 \\
(-1.614)\end{array}$ & $\begin{array}{l}-0.045 \\
(-1.543)\end{array}$ & $\begin{array}{l}0.099 * * * \\
(3.415)\end{array}$ & $\begin{array}{l}0.127^{* *} \\
(2.324)\end{array}$ \\
\hline Share of complex insurance products & $\begin{array}{c}0.073 \\
(0.353)\end{array}$ & $\begin{array}{c}-0.313 \\
(-1.290)\end{array}$ & $\begin{array}{c}0.408 * \\
(1.746)\end{array}$ & $\begin{array}{l}1.187^{* *} \\
(2.630)\end{array}$ \\
\hline $\begin{array}{l}\text { Member in a professional } \\
\text { organization }(\text { yes }=1)\end{array}$ & $\begin{array}{c}0.087 \\
(0.864)\end{array}$ & $\begin{array}{l}-0.281 * * \\
(-2.149)\end{array}$ & $\begin{array}{l}-0.160 \\
(-1.363)\end{array}$ & $\begin{array}{l}0.347 \\
(1.5609)\end{array}$ \\
\hline Constant & $\begin{array}{l}-1.359 * * * \\
(-9.446)\end{array}$ & & & $\begin{array}{l}-1.933 * * * \\
(-6.054)\end{array}$ \\
\hline Estimation method & OLS & $\begin{array}{l}\text { ML - Ordered } \\
\text { Probit }\end{array}$ & $\begin{array}{l}\text { ML - Ordered } \\
\text { Probit }\end{array}$ & ML -Binary Logit \\
\hline$N$ & 296 & 374 & 428 & 423 \\
\hline$R^{2}$ (adjusted) & 0.1621 & & & $0.0839^{\mathrm{b}}$ \\
\hline $\begin{array}{l}\text { LR statistic } \\
\text { (Prob (LR stat)) }\end{array}$ & $\begin{array}{l}12.418^{\mathrm{c}} \\
(0.000)\end{array}$ & $\begin{array}{l}25.646 \\
(0.000)\end{array}$ & $\begin{array}{l}22.894 \\
(0.000)\end{array}$ & $\begin{array}{l}47.961 \\
(0.000)\end{array}$ \\
\hline
\end{tabular}

${ }^{a}$ Measured in log-odds form: $\log$ (share of working time spent on information gathering/ (1-share of working time on information gathering).

${ }^{\mathrm{b}}$ McFadden $R^{2}$.

${ }^{\mathrm{c}} F$ statistic and $(\operatorname{Prob}(F$ stat $))$, Estimated with "EViews 5.0".

Note: *significant on 10 percent level, **significant on 5 percent level, and $* * *$ significant on 1 percent level; $z$-values in parentheses ( $t$-values in case of model 1).

The dependent variables range between 0 and 1 for models 1,5 , and 7 . Since the variables are continuously distributed between 0 and 1, ordinary least squares (OLS) regressions were estimated for these models. The dependent variables were expressed in log-odds form to accommodate better the requirements of an OLS-estimation. ${ }^{25}$ The dependent variables in models 2 and 3 are ordinal variables ranging from 1 to 5 ,

the response bias occurs for all interviewees similarly, that is, that there is no systematic difference between the groups of exclusive and independent insurance agents.

${ }^{25}$ However, this approach has a shortcoming in that all cases in which the dependent variable takes either the value 0 or 1 are left out of the estimation, as the log-odds of the variable is not defined in those cases. However, in our study, this appears to be a problem only in the case of model 6 , where the dependent variable lapse rate of automobile insurance contracts takes the value 0 in nearly 46 percent of all cases. To avoid this problem, a small, positive value $(0.0001)$ was added to every observation of the dependent variable in this model. This is a common approach taken in the literature (e.g., Addison et al. (2001)). The estimation results remain very stable compared to the approach in which the dependent variable had not been transformed. The results of the sensitivity test are available on request from the author. 
Table 3 Estimation results - output quality indicators

\begin{tabular}{|c|c|c|c|}
\hline & $\begin{array}{c}\text { Model 5: } \\
\text { Contract } \\
\text { conclusion rate }\end{array}$ & $\begin{array}{c}\text { Model 6: } \\
\text { Lapse rate } \\
\text { auto insurance }\end{array}$ & $\begin{array}{c}\text { Model 7: Share } \\
\text { of turnover } \\
\text { by new } \\
\text { customers }\end{array}$ \\
\hline Intermediary type (independent $=1$ ) & $\begin{array}{l}1.075^{* * * *} \\
(7.110)\end{array}$ & $\begin{array}{l}-0.899 * * * \\
(-3.964)\end{array}$ & $\begin{array}{c}0.285 \\
(1.494)\end{array}$ \\
\hline Firm size & $\begin{array}{c}0.003 \\
(0.353)\end{array}$ & $\begin{array}{l}-0.010 * \\
(-1.899)\end{array}$ & $\begin{array}{l}-0.100 * * \\
(-3.328)\end{array}$ \\
\hline Product range & $\begin{array}{l}0.151^{* * * *} \\
(3.922)\end{array}$ & $\begin{array}{c}0.050 \\
(0.831)\end{array}$ & $\begin{array}{c}0.076^{*} \\
(1.686)\end{array}$ \\
\hline Share of complex insurance products & $\begin{array}{c}0.160 \\
(0.500)\end{array}$ & $\begin{array}{l}-2.973 * * \\
(-7.128)\end{array}$ & $\begin{array}{l}1.279 * * \\
(3.118)\end{array}$ \\
\hline Member of professional organization (yes $=1$ ) & $\begin{array}{l}-0.155 \\
(-1.030)\end{array}$ & $\begin{array}{c}0.169 \\
(-0.734)\end{array}$ & $\begin{array}{l}0.584 * * \\
(2.573)\end{array}$ \\
\hline Share of private customers & & $\begin{array}{l}-1.588 * * \\
(-3.175)\end{array}$ & \\
\hline Professional experience & & & $\begin{array}{c}-0.009 \\
(-0.833)\end{array}$ \\
\hline Total lapse rate & & & $\begin{array}{c}5.331 \\
(0.343)\end{array}$ \\
\hline Constant & $\begin{array}{l}-0.670 * * * \\
(-3.093)\end{array}$ & $\begin{array}{l}-4.872^{* * *} \\
(-10.309)\end{array}$ & $\begin{array}{l}-2.110^{* * *} \\
(-6.180)\end{array}$ \\
\hline Estimation method & OLS & $\mathrm{OLS}^{\mathrm{a}}$ & OLS \\
\hline$N$ & 295 & 414 & 183 \\
\hline$R^{2}$ (adjusted) & 0.1826 & 0.1053 & 0.1600 \\
\hline$F$ statistic & 14.1371 & 9.1019 & 5.9511 \\
\hline$(\operatorname{Prob}(\mathrm{F}$ stat $))$ & $(0.000)$ & $(0.000)$ & $(0.000)$ \\
\hline
\end{tabular}

aWhite-heteroscedasticity corrected estimation. Estimated with "EViews 5.0".

Note: *significant on 10 percent level, **significant on 5 percent level, and $* * *$ significant on 1 percent level; $t$ values in parentheses. All dependent variables are measured in log-odds form (see model 1).

and 1 to 3, respectively. Thus, we estimate a Maximum Likelihood model for ordered variables (Ordered Probit). Finally, model 4 was estimated with a Maximum Likelihood Binary Logit model, since the dependent variable is binary.

Model 1 analyzes the influence of the independent variables on the share of working time spent on information acquisition. The results indicate that independent insurance brokers spend more of their working time on information gathering than do exclusive intermediaries. This can be interpreted to mean that they show a higher level of service intensity, as predicted by the product quality hypothesis. This result is highly significant at a 1 percent level.

Model 2 shows the result for the second quality indicator, the importance intermediaries attach to the information delivered by independent rating agencies. Again, independent intermediaries attach higher importance to information from independent rating agencies than exclusive agents do. ${ }^{26}$ The coefficient is significant at

\footnotetext{
${ }^{26}$ According to the coding of the variable Importance rating agencies, negative (positive) coefficients indicate a positive (negative) impact on service quality.
} 
a 1 percent level. As expected, the importance of independent information also increases with the membership in a professional organization, and the coefficient is significant at a 5 percent level.

The third model analyzes the design of the risk analysis. Here, independent intermediaries do not show a higher level of service quality. However, we find that a larger product range increases the probability that a computer-assisted risk analysis is conducted by the intermediary. A larger product range increases the requirements for information processing, so a more professional risk analysis is needed. Firm size does not show the expected sign: a growing firm size lowers the likelihood of a computerassisted risk analysis, although the size of the coefficient is very small. The results also show that an increasing share of complex insurance products in the intermediary's portfolio increases the professionalism with which the risk analysis is carried out.

Model 4 approximates the level of service quality based on whether a record of the counseling interview is prepared by the intermediary. Independent insurance brokers are more likely to make a record after a counseling interview. This relationship is highly significant at a 1 percent level. Further, as expected, a larger product range in the intermediary's portfolio raises the likelihood of record-keeping, showing a 5 percent significance level. The share of complex insurance products in the intermediary's portfolio also has a positive influence on the service quality, a relationship which is significant at a 5 percent level.

In addition to models 1-4, which seek to explain input indicators, models 5-7 use output performance indicators. Model 5 analyzes the contract conclusion rate after counseling interviews. Independent insurance agents realize higher contract conclusion rates compared to exclusive agents (level of significance: 1 percent). Further, the contract conclusion rate increases with a growing product range in the intermediary's portfolio, as could be expected.

Model 6 uses the second output quality indicator, the lapse rate in the automobile insurance line. This insurance line is well suited for an analysis of the lapse rate, as automobile insurance contracts can be cancelled comparatively easily at low cost, and significant lapse rates can be found in this insurance line. ${ }^{27}$ An additional exogenous variable which measures the share of private customers in the intermediary's portfolio (share of private customers) was included in this model because automobile insurance contracts are usually signed by private customers. ${ }^{28}$ Thus, this variable should be tested for the influence of the intermediary's specialization on private customers.

The results show that being an independent insurance broker lowers the chance of automobile insurance policies' being cancelled, indicating a better product choice by independent insurance agents compared to exclusive ones (level of significance:

\footnotetext{
${ }^{27}$ We also examined lapse rate in long-term, more complex insurance lines (e.g., private health insurance, long-term life insurance policies). In all cases, the lapse rates were much smaller, and the models proved not to be significant overall. A reason for this result could be that cancellation of these kinds of insurance incurs much higher costs for the customer. Further, these insurance types are credence goods exhibiting large information asymmetries, which could also explain why the lapse rates are much smaller than those of the more standardized private automobile insurance.

28 This variable ranges between 0 and 1 and measures the ratio of private customers to the total number of customers in the intermediary's portfolio.
} 
1 percent). ${ }^{29}$ Further, a larger share of complex insurance products shows the expected influence on service quality: the lapse rate is reduced, with the relationship significant on a 5 percent level. This result shows that a large share of complex insurance products has a positive influence on the service quality of the intermediary, and that the effect also results in a lower lapse rate in the case of a more standardized insurance line like private automobile insurance. The variable share of private customers shows a negative coefficient (level of significance: 5 percent), indicating that intermediaries with a larger share of private customers have a lower lapse rate in the auto insurance line. This effect might be explained by learning and experience effects, which are realized with an increasing number of customers in a certain insurance line. Finally, a larger firm size also shows the expected negative effect on the lapse rate, although the relationship is significant only at a 10 percent level.

Finally, Model 7 analyzes the dependent variable share of turnover generated by new customers. An additional exogenous variable which measures the professional experience of the intermediary in years (professional experience) was included in this model. It is important to test the influence of the intermediary's professional experience in this case, as it can be hypothesized that intermediaries gain a larger share of their turnover from new customers at the beginning of their career because of the need to build a customer base. Thus, intermediaries with a longer working experience should obtain a smaller part of their turnover by new customers. Further, it is important to test for the influence of the share of contracts which were cancelled in the period (total lapse rate) in case this variable shows a positive influence on the share of turnover, indicating a lower, not higher, level of service quality. In that case, it would not indicate high growth resulting from a higher quality of service, and the variable could not serve as an indicator for the output quality.

The results of the model demonstrate that a higher share of turnover does not result from the cancellation of contracts by existing customers, since the included variable total lapse rate has no influence on the share of turnover by new customers. Hence, the share of turnover by new customers can be interpreted as serving as an indicator for higher growth and for higher output quality, as hypothesized. In this model, independent brokers do not have a higher share of new customers, that is, independent agencies do not grow faster compared to dependent agencies. However, the exogenous variables product range, share of complex insurance products and membership in a professional organization show the expected positive influence on the share of turnover by new customers. A broader product range and the focusing on complex insurance products lead to a higher demand by new customers, which may be explained by the increasing need of customers for old-age and health provision. Unexpectedly, an increasing firm size lowers the share of turnover generated by new customers.

To summarize, we find that, with two exceptions, independent agents provide a higher level of service quality as measured by the indicators under consideration. As to the additional exogenous variables, the share of complex insurance products has a

${ }^{29}$ According to the coding of the variableLapse rate auto insurance, negative (positive) coefficients indicate a positive (negative) impact on service quality. 
positive influence on the measured service quality in four of seven models. In the case of the input indicators, this influence may be explained by the fact that, for complex insurance products, intermediaries have to meet higher requirements in the acquisition and transfer of information. In the case of the output indicators, a larger share of complex insurance products results in a lower lapse rate, indicating a higher level of service quality. Further, the share of turnover by new customers increases with a larger share of complex products, which may reflect an increasing demand for complex insurance products in the fields of old-age and health provision. The expected influence is also found for the product range: A larger product range raises the service quality offered in models 3-5 and 7, which might indicate economies of scope realized during the acquisition and processing of information, as information about a customer's profile can be used for different products. Membership in a professional organization shows the expected influence on the level of service intensity and the performance in two cases (models 2 and 7), which partially confirms that intermediaries who meet the requirements for a membership in a professional organization deliver a higher service quality to their customers. The limitation of the positive influence of this variable to only two models may be explained by the fact that the different professional organizations vary in the level of requirements they impose on their members; hence, it may be that membership in a professional organization works only to a limited amount as a quality-signaling instrument. Finally, firm size does not seem to have a relevant positive influence on the indicators, it even shows a negative influence in two cases. Thus, the expected presence of increasing returns to scale during the acquisition and processing of information does not seem to be associated with a higher level of service intensity or performance. To summarize, there seems to be evidence that supports hypothesis 2 as well: All the additional exogenous variables show some positive influence on the indicators measured, although to a different extent.

As for hypothesis 3, the theoretical considerations in the section on the empirical design and estimation approach suggest that, if the product quality hypothesis holds true, there should be a separating equilibrium in the market for insurance intermediation in which independent agents would mediate more complex and less standardized products, and exclusive insurance agents would focus on selling more standardized products. Table 4 shows sample means of the share of single insurance lines in the intermediaries' portfolio for the groups of exclusive and independent agents. Old-age provisions, commercial insurance, industrial insurance, and private health insurance serve as proxies for complex insurance lines, and private property insurance, automobile insurance and private indemnity insurance represent more standardized insurance products. We tested for significant differences in the sample means by applying parametric $t$-tests.

The results partly confirm the hypothesis of a separating equilibrium: As expected, independent agents show significantly higher shares of turnover in complex insurance lines like old-age provisions and commercial insurance lines. By contrast, exclusive agents show significantly higher shares of turnover in the more standardized private property insurance line.

Surprisingly, exclusive agents show a significantly higher share of turnover in the private health insurance line compared to independent agents. This contrasts with our 
Table 4 Shares of turnover in different insurance lines

\begin{tabular}{|c|c|c|c|}
\hline & Exclusive agents & Independent agents & Total \\
\hline \multicolumn{4}{|c|}{ Complex insurance lines } \\
\hline \multicolumn{4}{|c|}{ Industrial insurance } \\
\hline Mean & 0.0153 & 0.0228 & 0.0186 \\
\hline (Std. dev.) & $(0.1126)$ & $(0.1055)$ & $(0.1094)$ \\
\hline \multicolumn{4}{|c|}{ Old-age provisions } \\
\hline Mean & 0.2305 & $0.2664 * *$ & 0.2454 \\
\hline (Std. dev.) & $(0.1965)$ & $(0.2260)$ & $(0.2098)$ \\
\hline \multicolumn{4}{|c|}{ Commercial insurance } \\
\hline Mean & 0.0645 & $0.0876^{* *}$ & 0.0742 \\
\hline (Std. dev.) & $(0.0969)$ & $(0.1084)$ & $(0.1024)$ \\
\hline \multicolumn{4}{|c|}{ Private health insurance } \\
\hline Mean & 0.0976 & $0.0658 * *$ & 0.0843 \\
\hline (Std. dev.) & $(0.1645)$ & $(0.0925)$ & $(0.1398)$ \\
\hline \multicolumn{4}{|c|}{ Standardized insurance lines } \\
\hline \multicolumn{4}{|c|}{ Private property insurance } \\
\hline Mean & 0.2330 & $0.1784 * *$ & 0.2170 \\
\hline (Std. dev.) & $(0.1403)$ & $(0.1296)$ & $(0.1392)$ \\
\hline \multicolumn{4}{|c|}{ Automobile insurance } \\
\hline Mean & 0.2521 & 0.2502 & 0.2513 \\
\hline (Std. dev.) & $(0.1805)$ & $(0.1829)$ & $(0.1813)$ \\
\hline \multicolumn{4}{|c|}{ Private indemnity insurance } \\
\hline Mean & 0.1337 & 0.1544 & 0.1398 \\
\hline (Std. dev.) & $(0.0869)$ & $(0.1177)$ & $(0.0971)$ \\
\hline
\end{tabular}

Note: ${ }^{* *}$ Differences in mean values between groups of exclusive and independent agents significant on a 5 percent level. Turnover is measured by the ratios of placed insurance policies in the different insurance lines to the total number of placed policies, as data about financial turnover are not available.

expectation that independent agents would dominate in this complex insurance line. An explanation could be that respondents included more standardized additional health contracts (e.g., additional travel health or dental health insurance contracts) with full-coverage private health insurance contracts under the category of private health insurance contracts. In the case of automobile insurance contracts, which are more standardized, a predominance of exclusive agents was expected, but there is little difference between the share of turnover in both groups, a finding which may be because automobile insurance contracts are often used as a first contact with customers, with the aim of building up a long-term relationship. Thus, both types of intermediaries are interested in selling this type of insurance.

The analysis of the share of turnovers in different insurance lines shows that independent agents are over-represented in some complex insurance lines. However, according to our data, exclusive agents do not sell primarily standardized insurance products. 


\section{Conclusions}

The coexistence of two different distribution systems in insurance markets has often been a subject of research in the past. In this study, the situation in the German market for insurance intermediation is analyzed: until the liberalization of the European insurance markets in 1994, exclusive, firm-owned agents were the dominant distribution channel in the German market but, since then, independent agents have gained importance. As a consequence of market liberalization and deregulation, the number of insurance products and providers has increased. At the same time, private health and old-age provision is gaining importance, as the public health and pension coverage is declining. Both facts lead to an increasing demand for intensive counseling and high-quality advisory services by the customers. This study gives an answer to the question of whether independent insurance intermediaries are better able than dependent agents to perform these tasks, and to mediate complex insurance products.

To test the product quality hypothesis, the service intensity and the performance by independent and exclusive agents are analyzed. The results of an online survey among 608 German insurance intermediaries are used to obtain indicators for the service intensity (input quality indicators) and the performance (output quality indicators) of the intermediaries, and the influence of the intermediary type and other exogenous variables on the service quality indicators is analyzed.

The results of our analysis show that the product quality hypothesis holds true in the German life insurance market when exclusive and independent insurance intermediaries are compared with each other: in five of seven analyzed models, independent agents show higher levels of both input and output indicators compared to exclusive agents, thus providing evidence for superior service intensity and performance. Service intensity and performance also increases with a growing share of complex insurance products in the intermediary's portfolio, and the number of additional services an intermediary provides has a positive effect on the quality indicators. This result has also been found by Eckardt, where the number of additional services an intermediary provides had a positive influence on the information quality provided and the contract conclusion rate. ${ }^{30}$ Positive influence of membership in a professional organization is limited to two models. A possible explanation for this comparatively weak effect may lie in the large differences in the requirements imposed on members of professional organizations. Finally, the effect of firm size on the measured quality indicators is also weak, a result previously confirmed by an empirical study on the U.S. insurance market that found only limited evidence for the realization of economies of scale in insurance agencies. ${ }^{31}$ Eckardt also failed to find evidence for positive influence of firm size on information quality and contract conclusion rate in her study. ${ }^{32}$ The analysis of the insurance portfolios further indicates that the existence of a separating equilibrium in the market can be at least partially confirmed. Independent agents show larger market shares in most complex insurance lines,

\footnotetext{
${ }^{30}$ Eckardt (2007).

${ }^{31}$ Barrese and Nelson (1992).

${ }^{32}$ Eckardt (2007).
} 
whereas the dominance of exclusive agents in more standardized lines is supported only for private property insurance.

To summarize, independent agents seem to be able to deliver higher service intensity which translates into better performance, and this is of special importance in complex, long-term insurance products. This higher level of service intensity and output performance can explain the growing importance of this distribution channel after the liberalization of the market. As the importance of complex insurance products is expected to increase further in the future (particularly in the fields of private old-age and health provisions), it can also be expected that the importance of independent insurance agents will continue to increase in the German market.

However, due to missing information about the total population, the possibility of a selection bias cannot be excluded. Thus, as a task for future research, the survey could be re-conducted based on information obtained from the newly created central register for insurance intermediaries. From 2009 on, this register will contain information about every insurance intermediary operating in the German market. ${ }^{33}$ With this, it would be possible to test the sensitivity of the results to the sample selection.

The results of our study not only contribute to the explanation of the market structure in the German market for insurance intermediation but also are of special interest for consumers, professional organizations of insurance intermediaries, and consumer associations, as they answer the question about differences in service intensity and outcome in the market for insurance intermediation.

\section{Acknowledgements}

Thanks are due to Martina Eckardt, Christian Growitsch, Doris Neuberger, Carsten Ochsen, and two anonymous referees for helpful comments and suggestions.

\section{References}

Addison, J.T., Schnabel, C. and Wagner, J. (2001) 'Works councils in Germany: Their effects on establishment performance', Oxford Economics Papers 53: 659-694.

Anderson, E., Ross, W.T. and Weitz, B. (1998) 'Commitment and its consequences in the American agency system of selling insurance', Journal of Risk and Insurance 65: 637-669.

Barrese, J., Doerpinghaus, H.I. and Nelson, J.M. (1995) 'Do independent agent insurers provide superior service? The insurance marketing puzzle', Journal of Risk and Insurance 62: 297-308.

Barrese, J. and Nelson, J.M. (1992) 'Independent and exclusive agency insurers: A reexamination of the cost differential', Journal of Risk and Insurance 49: 375-397.

Berger, L.A., Cummins, J.D. and Weiss, M.A. (1997) 'The coexistence of multiple distribution systems for financial services: The case of property-liability insurance', Journal of Business 70: 515-546.

Berger, L.A., Kleindorfer, P.R. and Kunreuther, H. (1989) 'A dynamic model of the transmission of price information in auto insurance markets', Journal of Risk and Insurance 56: 17-33.

Cummins, J.D. and Doherty, N.A. (2006) 'The economics of insurance intermediaries', Journal of Risk and Insurance 73: 359-396.

Cummins, J.D. and VanDerhei, J. (1979) 'A note on the relative efficiency of property-liability insurance distribution systems', Bell Journal of Economics and Management 10: 708-719.

\footnotetext{
${ }^{33}$ See Federal Ministry of Justice (2007).
} 
Cummins, J.D. and Weisbart, S. (1977) The Impact of Consumer Services on Independent Insurance Agency Performance, Glenmont, New York: IMA Education and Research Foundation.

Dahlby, B. and West, D.S. (1986) 'Price dispersion in an automobile insurance market', Journal of Political Economy 94: 418-438.

Eckardt, M. (2002) Agent and broker intermediaries in insurance markets - An empirical analysis of market outcomes, Thünen Working Paper Series of Applied Economic Theory, 34, Rostock University, Rostock.

Eckardt, M. (2007) Insurance Intermediation: An Economic Analysis of the Information Services Market, Berlin and Heidelberg: Physica.

Etgar, M. (1976) 'Service performance of insurance distributors', Journal of Risk and Insurance 43: 487-499.

Federal Ministry of Justice (Bundesministerium der Justiz) (2007) 'Versicherungsvermittlungsverordnung vom 15. Mai 2007', Bundesgesetzblatt Jahrgang 1(20): 733-742.

Finsinger, J. and Schmid, F.A. (1994) 'Prices, distribution channels and regulatory intervention in European insurance markets', The Geneva Papers on Risk and Insurance - Issues and Practice 19: 22-36.

GDV (2002) GDV EVW-Datenbank Erhebung-Vertriebs-Wege, 1999/2000, Insgesamt, Gesamtbestand, mimeo.

GDV (2004) Jahrbuch 2004. Die deutsche Versicherungswirtschaft, Berlin: Verlag Versicherungswirtschaft.

Grieß, H.A. and Zinnert, M. (1997) Der Versicherungsmakler, Karlsruhe: Verlag Versicherungswirtschaft.

Grossman, S.J. and Hart, O.D. (1986) 'The costs and benefits of ownership: A theory of vertical and lateral integration', Journal of Political Economy 94: 691-719.

Joskow, P.L. (1973) 'Cartels, competition and regulation in the property-liability insurance industry', Bell Journal of Economics and Management 4: 375-427.

Klumpes, P.J.M. (2004) 'Performance benchmarking in financial services: Evidence from the UK life insurance industry', Journal of Business 77: 257-273.

Mayers, D. and Smith Jr., C. (1981) 'Contractual provisions, organizational structure, and conflict control in insurance markets', Journal of Business 54: 407-434.

Nell, M. and Traub, W. (1994) 'Die Haftung von Versicherungsmaklern als ökonomisches Problem', Zeitschrift für die gesamte Versicherungswissenschaft 83: 93-112.

Posey, L.L. and Tennyson, S. (1998) 'The coexistence of distribution systems under price search: Theory and some evidence from insurance', Journal of Economic Behavior and Organization 35: 95-115.

Regan, L. (1997) 'Vertical integration in the property-liability insurance industry: A transaction cost approach', Journal of Risk and Insurance 64: 41-62.

Regan, L. and Tennyson, S. (1996) 'Agent discretion and the choice of insurance marketing system', Journal of Law and Economics 39: 637-666.

Scheiper, S. (1996) Der Versicherungsmakler, Frankfurt a.M.: Peter Lang Publishing.

Weiss, M.A. (1990) 'Productivity growth and regulation of P/L insurance 1980-1984', Journal of Productivity Analysis 2: 15-38.

\section{About the Author}

Lucinda Trigo-Gamarra is a research assistant at the Chair of Money and Credit, Institute of Economics, University of Rostock, Germany. 